\title{
IMPACTOS DA IMPLANTAÇÃO DO BIM NO PROCESSO DE FABRICAÇÃO DIGITAL: ESTUDO DE CASO DE UMA FÁBRICA DE MÓVEIS MODULADOS 1
}

\author{
IMPACTS OF BIM IMPLEMENTATION IN DIGITAL FABRICATION: CASE \\ STUDY OF A CUSTOM CABINETRY COMPANY
}

\author{
Miguel Stehling \\ Programa de Pós-Graduação em Arquitetura, Tecnologia e Cidade, Universidade Estadual de \\ Campinas (UNICAMP) \\ miguelstehling@hotmail.com \\ Regina Ruschel \\ Faculdade de Engenharia Civil, Arquitetura e Urbanismo, Universidade Estadual de Campinas \\ (UNICAMP) \\ ruschel@fec.unicamp.br
}

\begin{abstract}
Resumo
O modelo BIM é uma representação digital das características físicas e funcionais de uma instalação e seus componentes. A Fabricação Digital é a utilização de máquinas CNC na execução de elementos construtivos. O objetivo deste estudo é avaliar os impactos da implantação BIM no sub-processo de projeto e fabricação digital de móveis personalizados. Trata-se de uma pesquisa exploratória realizada mediante observação e análise de documentos e processos de um Estudo de Caso de uma fábrica de móveis de cozinha personalizados. Os processos praticados pela empresa são comparados com os propostos em BIM Project Execution Planning Guide proposto pelo Computer Integrated Construction Research Program da Pennsylvania State University,mediante mapas representados segundo o padrão BPMN. Os processos são agrupados em quatro fases: anteprojeto, projeto básico, projeto executivo e fabricação. As diferenças na implantação BIM são agrupadas em quatro categorias: escopo da atividade, ferramentas, agentes e produto; e classificadas de acordo com alternativas incrementais de modificação. Observou-se que os impactos são consideráveis, de médio para alto, sendo médio nas categorias Escopo da atividade e Produtos, e alto nas categorias Ferramentas (dispositivo físico ou mental) e Agentes (departamentos ou indivíduos). Além deste diagnóstico, para o caso estudado, destaca-se como contribuições deste estudo a geração de tabelas de impactos na implantação de BIM, a pontuação destes impactos e a criação de cenários de impactos.
\end{abstract}

Palavras-chave: Fabricação digital. BIM. Controle numérico computadorizado.

\begin{abstract}
The BIM model is a digital representation of the physical and functional characteristics of a facility and its elements. Digital fabrication is the use of CNC machines in manufacturing facility elements. This study aims to evaluate the impacts of BIM implementation in the Digital Fabrication of custom cabinetry which is a sub process within the Building Design and Construction process. This study is exploratory conducted by observation, documents and process analysis through a Case Study of a custom cabinetry company. The processes practiced by the company are compared with the proposed in BIM Project Execution Planning Guide developed by Computer Integrated Construction Research Program of the Pennsylvania State University, through process maps drawn according BPMN standard. The processes were grouped into four phases: schematic design, design development,
\end{abstract}

\footnotetext{
1 STEHLING, M; RUSCHEL, R. Impactos da implantação do BIM no processo de fabricação digital: Estudo de caso de uma fábrica de móveis modulados. In: ENCONTRO BRASILEIRO DE TECNOLOGIA DE INFORMAÇÃO E COMUNICAÇÃO NA CONSTRUÇÃO, 7., 2015, Recife. Anais... Porto Alegre: ANTAC, 2015.
} 
construction documents and fabrication. In these phases the differences in BIM implementation are grouped into four categories: activities scope, tools, agents and products; and are classified according to alternative impact magnitude. It was observed that the impacts are substantial, from moderate to high. Moderate in the Scope and Product categories, and high in Tools (physical or mental device) and Agents (individuals or departments) categories. In addition to this, it stands out as contributions of this study the generation of impact tables, scores and scenarios.

Keywords: Digital fabrication. BIM. Computer numerical control.

\section{INTRODUÇÃO}

A Modelagem da Informação da Construção (BIM) é uma emergente mudança tecnológica e procedimental dentro da indústria da Arquitetura, Engenharia, Construção e Operação tendo como produto uma representação digital das características físicas e funcionais de uma instalação e seus componentes. A Fabricação Digital é a utilização de máquinas de Controle Numérico Computadorizado (CNC) na execução de elementos construtivos. Este estudo é parte de projeto de pesquisa de doutorado cujo objetivo é avaliar o impacto da implantação de BIM no processo de fabricação digital na construção civil dando ênfase ao sub-processo de projeto e fabricação de móveis personalizados. Inicia-se este estudo pela avaliação de um Estudo de Caso de uma fábrica de móveis modulados personalizados na qual um dos autores desenvolveu o sistema de fabricação digital em sistema CAD/CAM e a empresa deseja implantar BIM. A empresa é consolidada em seu nicho de mercado, adota as soluções técnicas mais avançadas disponíveis e projeta e fabrica no sistema de Personalização em Massa.

É tomado como protocolo a adaptação do guia de implantação BIM definido em CIC (2011). Os Mapas dos Processos utilizados nas análises são elaborados segundo o padrão Business Process Model and Notation (BPMN). São elaborados os mapas dos processos adotados pela empresa e os mapas dos processos propostos pelo guia BIM Project Execution Planning Guide (CIC, 2011).

Por meio de uma análise comparativa de mapas, observações e análise de documentos, são identificadas diferenças entre atividades, ferramentas, produtos e agentes (denominadas categorias). As atividades são agrupadas nas fases de projeto adotadas pela empresa: (i) Anteprojeto, (ii) Projeto Básico, (iii) Projeto Executivo e (iv) Fabricação. As diferenças identificadas são agrupadas nas quatro categorias e classificadas conforme a intensidade do impacto: (i) no Escopo da Atividade (trabalhos ou ações) onde o escopo pode permanecer inalterado, ter alteração parcial ou total, recebendo respectivamente pontuação de baixo, médio ou alto impacto, (ii) nas Ferramentas que podem variar de um dispositivo físico e/ou mental, um dispositivo CAD/CAM ou um software BIM, recebendo respectivamente pontuação de baixo, médio ou alto impacto, (iii) nos Produtos que podem variar de um artefato físico e/ou intelectual, um código CAM, ou geometria associada a banco de dados, recebendo respectivamente pontuação de baixo, médio ou alto impacto, e (iv) nos Agentes (entidades, departamentos ou indivíduos) podendo a competência requerida dos mesmos permanecer inalterada, ter alteração parcial ou profunda, recebendo respectivamente pontuação de baixo, médio ou alto impacto.

\section{FUNDAMENTAÇÃO}

Succar (2009) define Modelagem da Informação da Construção (BIM) como um conjunto interelacionado de políticas, processos e tecnologias que geram uma metodologia para gerenciar os projetos essenciais de uma edificação e os dados do empreendimento num formato digital em todo o ciclo de vida da edificação. Segundo Gershenfeld (2012) Fabricação Digital é a programação computacional da produção de objetos físicos, e as raízes desta tecnologia remontam à década de 1950 quando pesquisadores do Massachusetts Institute of 
Technology (MIT) ligaram um computador digital a uma fresadora criando a primeira máquina de Controle Numérico Computadorizado-Computer Numerical Control (CNC).

Kolarevic (2003) afirma que a Fabricação Digital atribui ao arquiteto uma nova maneira de projetar e chegar ao produto final, pela extrapolação da simples representação no CAD (Computer Aided Design) para a exploração do CAM (Computer Aided Manufacturing) na fabricação de maquetes e execução de elementos construtivos. Conforme CIC (2011, p.57), algumas aplicações de BIM em fabricação digital podem ser vistas em estruturas metálicas e cortes de tubos, reduzindo ambiguidades e desperdícios no processo de produção.

Nahmens e Bindroo (2011) revelam que a personalização de um produto proporciona índices maiores de satisfação do cliente, mas na indústria da construção o desempenho diminui com o aumento da personalização. Porém Gershenfeld (2012) afirma que a Fabricação Digital favorece a Personalização em Massa (Mass Customization) ao permitir o projeto e a produção conforme a demanda. Conforme Eastman et al (2008, p.244-245), BIM proporciona mudanças fundamentais nos processos de projeto e produção, pois oferece a capacidade de se gerenciar o grande volume de informações necessario à Personalização em Massa. Eastman et al (2008, p.178-180) afirmam que projetar e produzir partes de um edifício utilizando-se máquinas CNC é uma área de estudo com alta demanda de atenção tanto por escolas de arquitetura quanto empresas inovadoras.

A Figura 1 apresenta um procedimento estruturado em quatro etapas sugerido pelo guia BIM (CIC, 2011), visando guiar o desenvolvimento de um plano de Execução de Empreendimentos BIM. O primeiro passo é identificar claramente os usos BIM conforme o tipo do empreendimento ou conforme o objetivo de treinamento dos membros das equipes técnicas. Por uso BIM entende-se um processo que pode se beneficiar com a implantação de BIM. O segundo passo é o desenvolvimento de mapas que contenham os processos e as informações trocadas entre eles. Inicialmente desenha-se um mapa geral e em seguida elabora-se mapas detalhados de cada processo. A terceira etapa é a definição das trocas de informações entre processos e os responsáveis por elas. O último passo é determinar a infraestrutura necessária para se garantir a qualidade dos Modelos BIM, por exemplo software, hardware, instalações e treinamento de pessoal (CIC, 2011).

Figura 1 -Planejamento da Execução de um Empreendimento em BIM

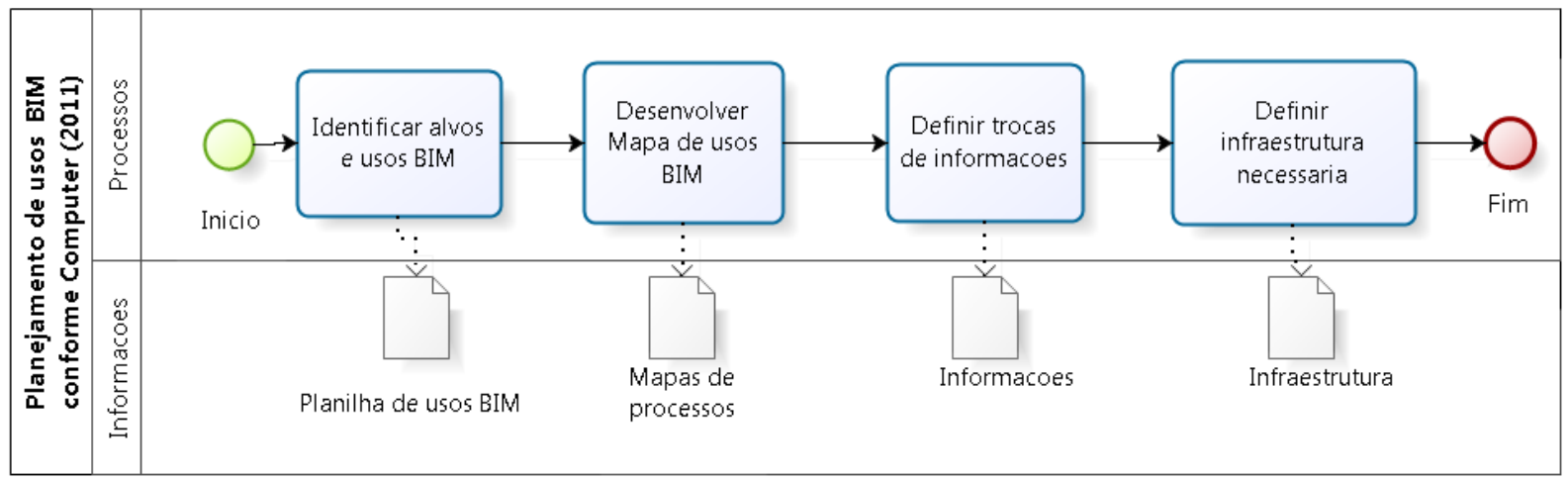

Fonte: adaptado de $\mathrm{CIC}(2011, \mathrm{p} .3)$

O estudo apresentado neste artigo dá ênfase à segunda etapa do planejamento da execução de um empreendimento em BIM avaliando mapas de processos que serão desenhados no padrão BPMN. Segundo White (2004) o padrão BPMN é um modelo de representação de processos de negócios, baseado em técnica de fluxograma composto de símbolos representativos de atividades e fluxos de controle organizados visualmente de forma a facilitar a identificação dos agentes. 


\section{MÉTODO}

O delineamento deste Estudo de Caso é apresentado na Figura 2 compondo seis etapas: (i) na primeira etapa trata-se da formulação do problema que neste estudo é resumido na seguinte questão: de que forma BIM impacta o processo de fabricação digital? (ii) na segunda etapa trata-se da definição das unidades-caso que neste estudo será a fabricação digital de móveis planejados; (iii) na terceira etapa realiza-se a seleção do número de casos, que neste estudo exploratório será um caso específico de uma empresa que já aplica CAD/CAM para fabricação digital de móveis com o processo de personalização em massa (mass customization) e deseja implantar a tecnologia BIM; (iv) na quarta etapa elabora-se o protocolo de análise que inclui: o processo proposto por CIC (2011) incorporando o sub-processo de projeto de móveis e um critério de classificação das diferenças entre cenários de mudanças com a adoção de BIM e impacto resultante (Tabela 1); (v) na quinta etapa, a Coleta de dados, elabora-se mediante observação e análise de documentos o mapa do processo adotado pela empresa no padrão BPMN; (vi) na sexta etapa, compara-se os mapas dos processos (da empresa e do guia) identificando-se as diferenças, agrupada-as conforme atividades (trabalhos ou ações), ferramentas (softwares ou outros recursos), produtos (documentos, modelos, dados ou artefatos) e agentes (entidades, departamentos ou indivíduos participantes no processo). A interpretação dos dados é feita com base na pontuação segundo o nível de intensidade do impacto: (1) baixo impacto; (2) médio impacto; (3) alto impacto. As diferenças são classificadas conforme o impacto resultante.

Figura 2 - Delineamento: Etapas do estudo

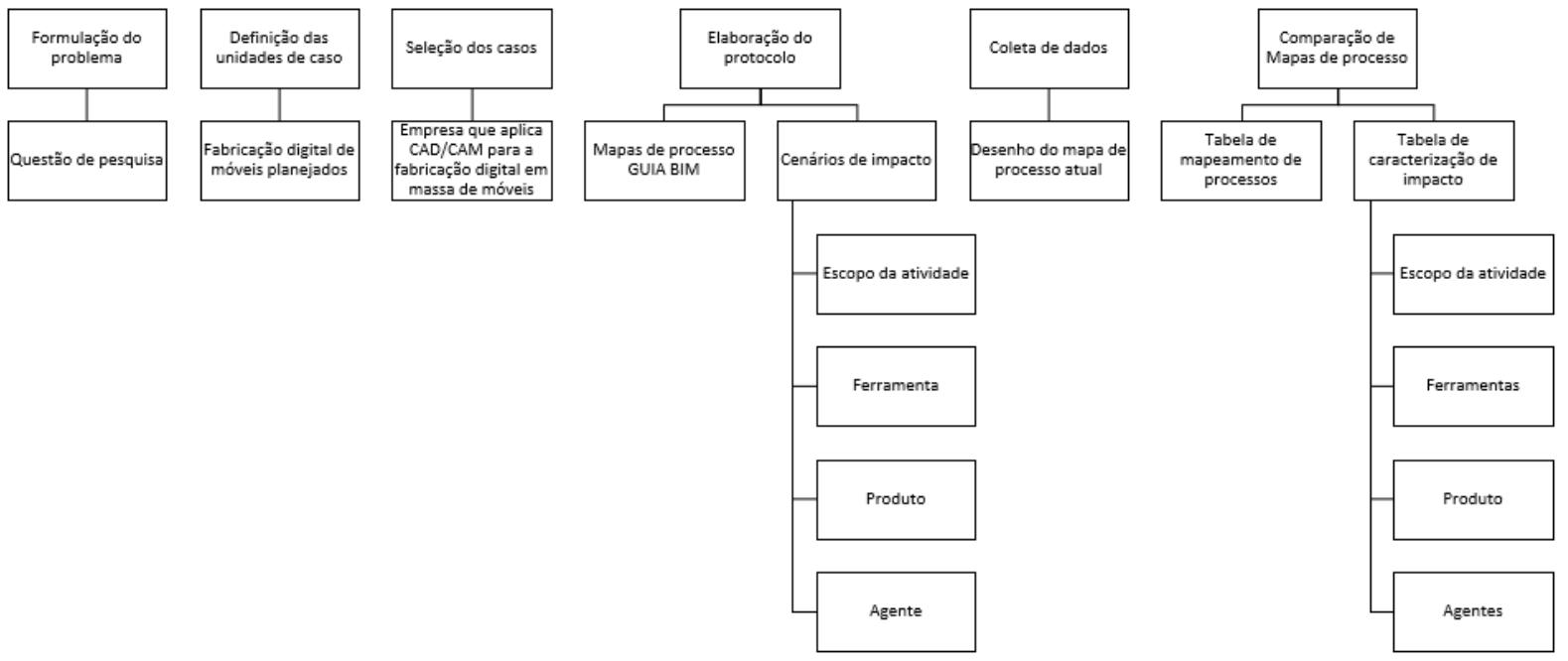

Fonte: os autores

Tabela 1 - Critério de classificação das diferenças quanto ao impacto resultante

\begin{tabular}{lllll}
\hline $\begin{array}{l}\text { Escopo da } \\
\text { Atividade }\end{array}$ & Ferramenta & Produto & Agente & Impacto \\
\hline $\begin{array}{l}\text { Permanece } \\
\text { inalterada }\end{array}$ & $\begin{array}{l}\text { Dispositivo físico } \\
\text { ou mental }\end{array}$ & $\begin{array}{l}\text { Artefato físico ou } \\
\text { intelectual }\end{array}$ & $\begin{array}{l}\text { Competência } \\
\text { inalterada }\end{array}$ & 1 = baixo impacto \\
\hline $\begin{array}{l}\text { Alterada } \\
\text { parcialmente }\end{array}$ & CAD / CAM & $\begin{array}{l}\text { Desenho 2D ou } \\
\text { código CAM }\end{array}$ & $\begin{array}{l}\text { Competência } \\
\text { parcialmente } \\
\text { alterada }\end{array}$ & 2 = médio impacto \\
\hline $\begin{array}{l}\text { Nova ou totalmente } \\
\text { alterada }\end{array}$ & Software BIM & $\begin{array}{l}\text { Geometria e banco } \\
\text { de dados }\end{array}$ & $\begin{array}{l}\text { Competência } \\
\text { profundamente } \\
\text { alterada }\end{array}$ & 3 = alto impacto \\
\hline
\end{tabular}


A escolha da empresa para o Estudo de Caso é fundamentada no fato de ser líder em seu ramo de atuação, além de estar há mais de duas décadas no mercado.

\section{RESULTADOS E DISCUSSÃO}

O processo de projeto e produção na empresa objeto deste estudo constitui-se em quatro fases: Anteprojeto, Projeto Básico, Projeto Executivo e Fabricação, conforme ilustrado na figura 3. O Anteprojeto, executado por arquitetos, gera uma representação genérica da volumetria, do layout e arranjo funcional do ambiente, da definição do tipo de cada módulo, bem como de suas dimensões aproximadas. Estas informações são utilizadas na determinação da estimativa de custos para elaboração do preço do produto. O Projeto Básico é executado por arquitetos após a assinatura do contrato com o cliente. É feita a checagem definitiva das dimensões do ambiente e de cada elemento do projeto. Nesta fase é feita a conferência final de dimensões e especificações técnicas de instalação de eletrodomésticos utilizados, dispositivos e acessórios incorporados no produto. O Projeto Executivo é desenvolvido por engenheiros. Nesta fase são elaborados os detalhes construtivos de cada módulo, e a partir destes detalhes, são gerados os códigos de Controle Numérico Computadorizado, Computer Numerical Control - CNC para fabricação digital. Faz parte do projeto executivo a elaboração de desenhos de detalhes de montagem dos módulos nas instalações do cliente. $\mathrm{Na}$ fase de Fabricação a empresa utiliza máquinas $\mathrm{CNC}$ para corte $2 \mathrm{D}$ (serra de mesa) e para corte 3D (fresadora de 3 eixos).

Figura 3 - Fases do processo de projeto e produção

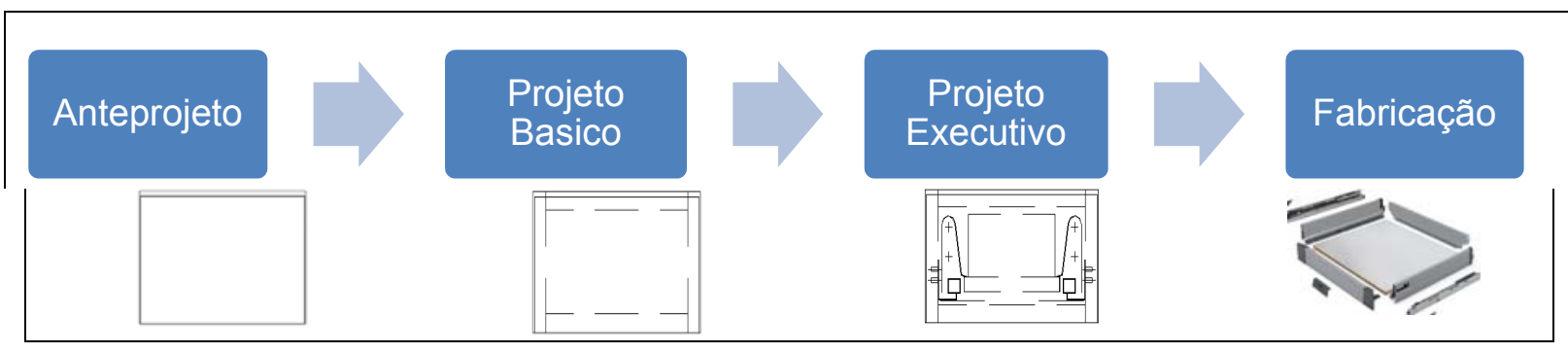

Fonte: os autores

A Figura 4 apresenta o mapa geral do processo adotado pela empresa objeto deste estudo. Diferencia-se neste desenho as atividades de projeto das atividades de construção compostas por: fabricar, montar e instalar os móveis. Neste estudo dá-se ênfase às atividades de projeto que na Figura 5 são mapeadas para o processo de projeto incorporando BIM proposto por CIC (2011).

Figura 4 - Processo adotado pela empresa - mapa geral - Nível 1

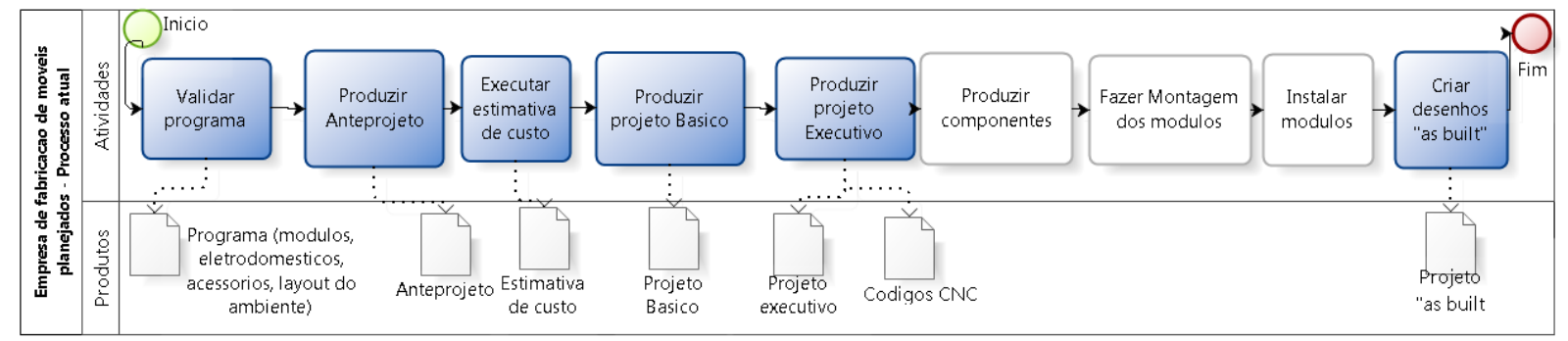

Fonte: os autores

A Figura 5 mostra o mapa geral de processo de execução BIM sugerido pelo Guia BIM (CIC, 2011), adaptado para a indústria de móveis modulados em estudo. Neste redesenho percebe- 
se um baixo mapeamento de atividades do sub-processo existente, demarcado em azul na Figura 5, dentro do processo da construção civil,.

Figura 5 - Processo de execução BIM - mapa geral - Nível 1

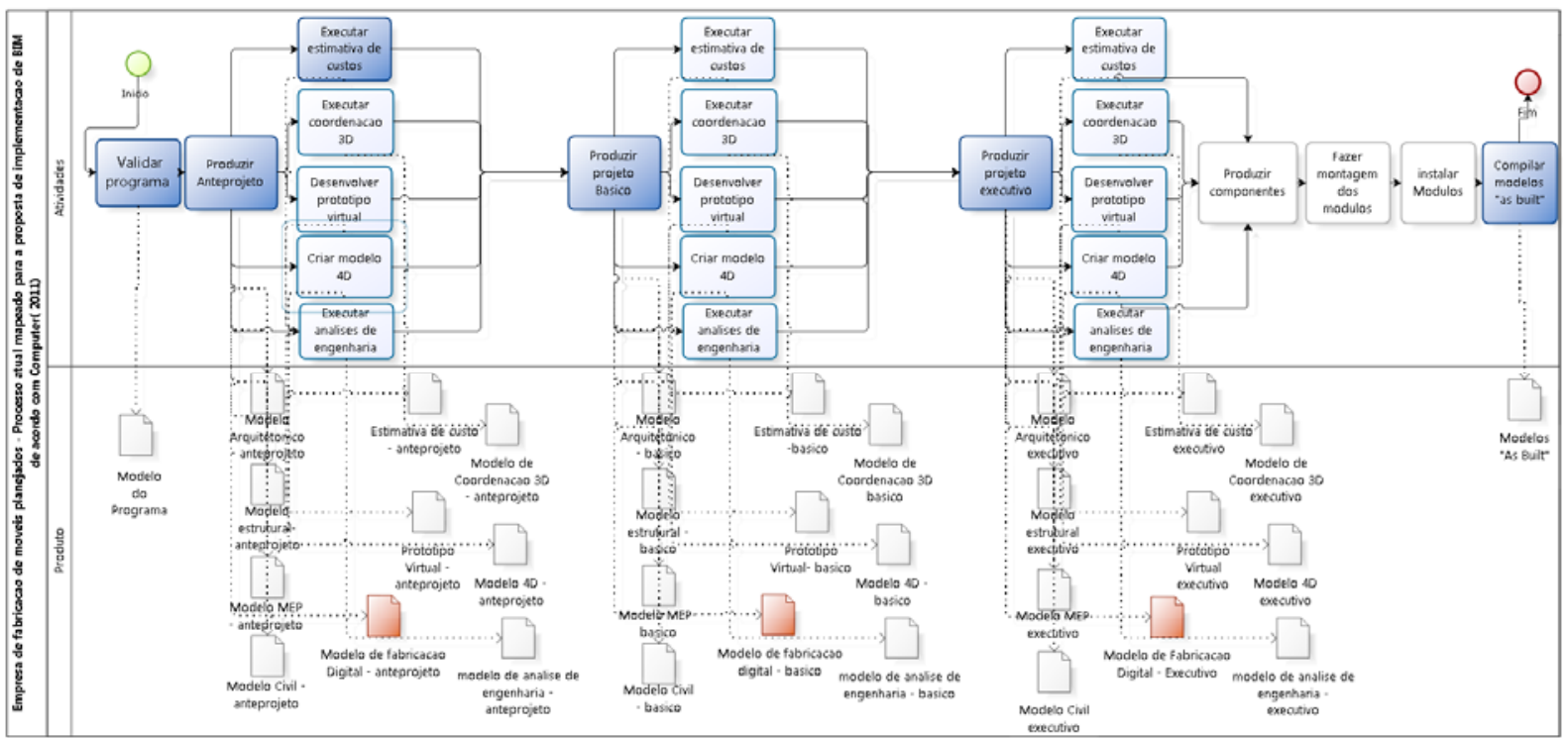

Fonte: adaptado de CIC (2011, p.75)

O sub-processo de projeto e produção de móveis modulados na empresa objeto deste estudo termina com a criação de documentos "as built" conforme mostram a Figura 4 e Figura 5. Esta atividade corresponde ao arquivamento de todos os desenhos e especificações de projetos que correspondem ao histórico evolutivo desde a concepção do empreendimento até à instalação final de todos os módulos. Este procedimento visa dar suporte em ações da empresa na eventualidade de litígios, dirimir dúvidas relativas a responsabilidades ao longo do processo e fornecer informações necessárias em manutenções corretivas oferecidas pela empresa durante o prazo de 5 anos de garantia de seus produtos. Com a implantação BIM vislumbra-se a criação de um modelo "as built" a partir do modelo de Produção alterado conforme modificações feitas nos processos de fabricação e instalação. As atividades de desenvolvimento de protótipo virtual anteprojeto, protótipo virtual de projeto básico e protótipo virtual de projeto executivo mostradas na Figura 5, a partir dos modelos de anteprojeto, projeto básico e projeto executivo respectivamente, não possuem correspondentes no sistema adotado pela empresa.

De acordo com o guia proposto por CIC (2011) mostrado em Figura 1, o primeiro passo para o Planejamento da Execução de um Empreendimento em BIM é identificar claramente os usos BIM e o produto deste processo é uma planilha de usos BIM. Os usos BIM que se aplicam à empresa objeto deste estudo estão identificados em uma planilha mostrada na Tabela 2. A primeira coluna mostra as fases do ciclo de vida do empreendimento. A segunda coluna identifica cada Potencial uso BIM a ser implantado. Foram considerados os usos BIM em todo o ciclo de vida de uma cozinha planejada, que começa com a validação do programa e culmina com a geração de um modelo "as built" 3D que será uma evolução dos documentos "as built" 2D que a empresa produz atualmente. A terceira coluna apresenta para cada potencial uso BIM a sua descrição e respectivos objetivos. Na quarta coluna foram definidas as prioridades da implantação de cada uso BIM. Estas prioridades são decorrentes da necessidade imediata da empresa que é a integração dos processos de projeto ao sistema de Fabricação Digital. Os ítens classificados com prioridade alta, média e baixa refletem o plano de implantação cada uso BIM a curto, médio ou longo prazos. 
Tabela 2 - Planilha de usos BIM

\begin{tabular}{|c|c|c|c|}
\hline Fase & Potencial uso BIM & Descrição / Objetivos & $\begin{array}{l}\text { Prioridade (alta } \\
\text { /media/ baixa) }\end{array}$ \\
\hline \multirow{6}{*}{$\begin{array}{l}\frac{0}{.0} \\
\frac{0}{0} \\
\frac{0}{0} \\
\frac{1}{\frac{1}{c}}\end{array}$} & Validação do programa & $\begin{array}{c}\text { Coletar informações e definir materiais, layout do ambiente, } \\
\text { eletrodomésticos e acessórios. }\end{array}$ & Alta \\
\hline & Produzir Anteprojeto & $\begin{array}{c}\text { Estudar as definições geométricas conceituais de cada módulo } \\
\text { do ambiente projetado. Gerir biblioteca de elementos 3D } \\
\text { paramétricos para anteprojeto. }\end{array}$ & Alta \\
\hline & Executar estimativa de custos & $\begin{array}{l}\text { Geração rápida de quantitativos para ajudar no processo } \\
\text { decisório objetivando margem de incerteza } 30 \% \text {. Associar custos } \\
\text { aos quantitativos, incorporar custo indireto e imprevistos }\end{array}$ & Alta \\
\hline & Desenvolver protótipo virtual & $\begin{array}{l}\text { Gerar modelo 3D com nível de detalhe - LOD } 100 \text { que consiste } \\
\text { em volumetria geral, posicionamentos, locações, e informações } \\
\text { primárias básicas. }\end{array}$ & Alta \\
\hline & Criar modelo 4D & $\begin{array}{c}\text { Cronograma de investimentos e disponibilidade de recursos com } \\
\text { base no protótipo virtual LOD } 100\end{array}$ & Baixa \\
\hline & $\begin{array}{l}\text { Desenvolver simulação de } \\
\text { iluminação }\end{array}$ & Visualizações dos pontos de iluminação no ambiente projetado & Baixa \\
\hline \multirow{5}{*}{ 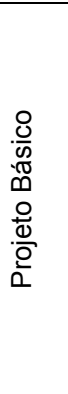 } & Produzir Projeto Básico & $\begin{array}{c}\text { Definições geométrica precisas de cada módulo do ambiente } \\
\text { projetado. Gerir biblioteca de elementos 3D paramétricos para } \\
\text { projeto básico. }\end{array}$ & Alta \\
\hline & Desenvolver orçamento básico & $\begin{array}{l}\text { Orçamento realizado com base nas especificações técnicas } \\
\text { preliminares com margem de incertezas } 15 \% \text {. Associar custos } \\
\text { aos quantitativos, incorporar custo indireto e imprevistos. }\end{array}$ & Média \\
\hline & Desenvolver protótipo virtual & $\begin{array}{c}\text { Módulo com nível de detalhe - LOD 300, com geometrias, } \\
\text { quantitativos e dimensões precisas. }\end{array}$ & Alta \\
\hline & Criar modelo 4D & $\begin{array}{c}\text { Cronograma de investimentos e disponibilidades de recursos com } \\
\text { base no protótipo virtual LOD } 300 .\end{array}$ & Baixa \\
\hline & $\begin{array}{l}\text { Desenvolver simulação de } \\
\text { iluminação }\end{array}$ & $\begin{array}{c}\text { Visualização dos pontos de iluminação no ambiente projetado } \\
\text { acrescida do projeto elétrico. }\end{array}$ & Baixa \\
\hline \multirow{4}{*}{ 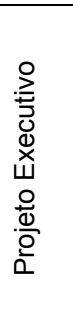 } & Produzir Projeto Executivo & $\begin{array}{l}\text { Definições de detalhes geométricos precisos necessários para a } \\
\text { elaboração do projeto de produção(“Shop drawings"). Gerir } \\
\text { biblioteca de elementos 3D paramétricos para projeto executivo. }\end{array}$ & Alta \\
\hline & $\begin{array}{l}\text { Desenvolver orçamento } \\
\text { detalhado }\end{array}$ & $\begin{array}{c}\text { Orçamento realizado com base no modelo do projeto executivo } \\
\text { com margem de incerteza de } 5 \% \text {. Associar custos aos } \\
\text { quantitativos, incorporar custo indireto e imprevistos. }\end{array}$ & Média \\
\hline & Desenvolver protótipo virtual & $\begin{array}{l}\text { Geração de módulos com nível de detalhe LOD } 400 \text { - todos os } \\
\text { detalhes necessários para fabricação. }\end{array}$ & Média \\
\hline & Criar modelo 4D & $\begin{array}{c}\text { Geração de códigos de Fabricação Digital - máquinas CNC - } \\
\text { com base no protótipo virtual LOD } 400 .\end{array}$ & Alta \\
\hline $\begin{array}{l}\text { Ope } \\
\text { raç } \\
\text { ão }\end{array}$ & Compilar modelo "as built" & $\begin{array}{c}\text { Modelo que reflete o que foi construído. Destina-se à } \\
\text { manutenção, operação e "retrofit" }\end{array}$ & Baixa \\
\hline
\end{tabular}

Fonte: adaptado de CIC (2011, p.10)

A partir da comparação entre Figura 5 e Tabela 2 foi elaborada a Tabela 3 que mostra a equivalência entre atividades do processo da empresa em estudo (colunas 5 e 6) e do processo proposto pelo guia (colunas 2 e 3 ). A primeira coluna mostra as fases do ciclo de vida do empreendimento. A segunda e terceira colunas apresentam respectivamente as atividades e produtos relativos ao processo incorporando BIM. A coluna (4) demarca os processos contidos no guia proposto por CIC (2011). As colunas cinco e seis apresentam respectivamente as atividades e produtos relativos ao mapeamento para o sub-processo atual. A coluna (7) identifica os processos e produtos atualmente praticados pela empresa. A coluna (8) mostra os processos e produtos possíveis de incorporação no contexto da implantação BIM. A pontuação das colunas 4, 7 e 8 , obedece o seguinte princípio: valor "0" para ítens propostos pelo guia CIC (2011) que não se aplicam ao sub-processo de Fabricação Digital ou que não são desenvolvidos pela empresa, e valor "1" para ítens que se aplicam a Fabricação Digital ou para processos que a empresa já pratica. 
Tabela 3 - Processo de execução BIM - mapa geral - Nível 1

\begin{tabular}{|c|c|c|c|c|c|c|c|}
\hline \multirow{2}{*}{$\begin{array}{l}\text { Fa } \\
\text { se } \\
(1) \\
\end{array}$} & \multicolumn{2}{|c|}{ Processo incorporando BIM ( } & \multirow{2}{*}{ (4) } & \multicolumn{2}{|c|}{ Mapeamento para o processo atual } & \multirow{2}{*}{ (7) } & \multirow{2}{*}{ (8) } \\
\hline & (2) & (3) & & (5) & (6) & & \\
\hline \multirow{10}{*}{$\begin{array}{l}\frac{0}{5} \\
\frac{1}{5} \\
0 \\
\frac{x}{2} \\
\frac{1}{W} \\
\sum \\
\frac{1}{\sigma}\end{array}$} & Validar programa & Modelo do programa & 1 & Validar programa & $\begin{array}{l}\text { Informações do } \\
\text { programa (módulos, } \\
\text { eletrodomésticos } \\
\text { acessórios e layout) }\end{array}$ & 1 & 1 \\
\hline & \multirow[t]{4}{*}{ Produzir Anteprojeto } & $\begin{array}{l}\text { Modelo arquitetonico } \\
\text { anteprojeto }\end{array}$ & 1 & \multirow[t]{4}{*}{ Produzir Anteprojeto } & $\begin{array}{c}\text { Modelo } \\
\text { arquitetonico } \\
\text { anteprojeto }\end{array}$ & 1 & 1 \\
\hline & & Modelo MEP anteprojeto & 1 & & Anteprojeto elétrico & 0 & 1 \\
\hline & & $\begin{array}{l}\text { Modelo estrutural } \\
\text { anteprojeto }\end{array}$ & 1 & & Não é desenvolvido & 0 & 1 \\
\hline & & Modelo civil anteprojeto & 1 & & Não se aplica & 0 & 0 \\
\hline & $\begin{array}{c}\text { Executar estimativa de } \\
\text { custos }\end{array}$ & $\begin{array}{c}\text { Estimativa de custos - } \\
\text { anteprojeto }\end{array}$ & 1 & $\begin{array}{c}\text { Executar estimativa de } \\
\text { custos }\end{array}$ & $\begin{array}{c}\text { Estimativa de } \\
\text { custos - anteprojeto }\end{array}$ & 1 & 1 \\
\hline & Executar coordenação 3D & $\begin{array}{l}\text { Modelo de coordenacao } 3 D \\
\text { - anteprojeto }\end{array}$ & 1 & $\begin{array}{c}\text { Atividade não se aplica } \\
\text { a este processo }\end{array}$ & Não se aplica & & \\
\hline & $\begin{array}{c}\text { Desenvolver protótipo } \\
\text { virtual }\end{array}$ & $\begin{array}{l}\text { Protótipo virtual - } \\
\text { anteprojeto }\end{array}$ & 1 & $\begin{array}{l}\text { Desenvolvimento do } \\
\text { protótipo }\end{array}$ & Modelo em cad 2D & 1 & 1 \\
\hline & Criar modelo 4D & Modelo 4D - anteprojeto & 1 & $\begin{array}{l}\text { Atividade não } \\
\text { desenvolvida }\end{array}$ & Não é desenvolvido & 0 & 1 \\
\hline & $\begin{array}{c}\text { Executar análises de } \\
\text { engenharia }\end{array}$ & $\begin{array}{c}\text { Modelo de análises de } \\
\text { engenharia - anteprojeto }\end{array}$ & 1 & $\frac{\text { desenvolvida }}{\text { Produzir projeto básico }}$ & Não é desenvolvido & 0 & 1 \\
\hline \multirow{9}{*}{$\begin{array}{l}0 \\
\frac{0}{w} \\
\frac{n}{\alpha} \\
0 \\
0 \\
\frac{w}{2} \\
\frac{0}{2} \\
\frac{1}{2}\end{array}$} & \multirow[t]{4}{*}{ Produzir projeto básico } & $\begin{array}{l}\text { Modelo arquitetonico- } \\
\text { básico }\end{array}$ & \multirow{4}{*}{$\frac{1}{1}$} & \multirow[t]{4}{*}{ Produzir projeto básico } & Projeto básico & 1 & 1 \\
\hline & & Modelo MEP -básico & & & Não se aplica & 0 & 0 \\
\hline & & Modelo estrutural -básico & & & Não se aplica & 0 & 0 \\
\hline & & Modelo Civil -básico & & & Não se aplica & 0 & 0 \\
\hline & $\begin{array}{c}\text { Executar estimativa de } \\
\text { custos }\end{array}$ & $\begin{array}{c}\text { Estimativa de custos - } \\
\text { básico }\end{array}$ & 1 & $\begin{array}{l}\text { Atividade não } \\
\text { desenvolvida }\end{array}$ & Não é desenvolvido & 0 & 1 \\
\hline & Executar coordenação 3D & $\begin{array}{c}\text { Modelo de coordenacao 3D } \\
\text {-básico }\end{array}$ & 1 & $\begin{array}{c}\text { Atividade não se aplica } \\
\text { a este processo }\end{array}$ & Não se aplica & 0 & 0 \\
\hline & $\begin{array}{c}\text { Desenvolver protótipo } \\
\text { virtual }\end{array}$ & Protótipo virtual -básico & 1 & $\begin{array}{c}\text { Desenvolvimento do } \\
\text { protótipo }\end{array}$ & Modelo em cad 2D & 1 & 1 \\
\hline & Criar modelo $4 D$ & Modelo 4D -básico & 1 & $\begin{array}{l}\text { Atividade não } \\
\text { desenvolvida }\end{array}$ & Não é desenvolvido & 0 & 1 \\
\hline & $\begin{array}{c}\text { Executar análises de } \\
\text { engenharia }\end{array}$ & $\begin{array}{c}\text { Modelo de análises de } \\
\text { engenharia -básico }\end{array}$ & 1 & $\begin{array}{c}\text { desenvolvida } \\
\text { Produzir projeto } \\
\text { executivo }\end{array}$ & Não é desenvolvido & 0 & 1 \\
\hline \multirow{9}{*}{ 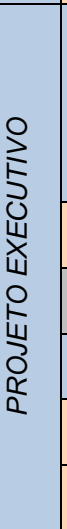 } & \multirow[t]{4}{*}{ Produzir projeto executivo } & $\begin{array}{c}\text { Modelo arquitetonico- } \\
\text { executivo }\end{array}$ & 1 & \multirow[t]{4}{*}{$\begin{array}{l}\text { Produzir projeto } \\
\text { executivo }\end{array}$} & Projeto preliminar & 1 & 1 \\
\hline & & Modelo MEP -executivo & 1 & & Não se aplica & 0 & 0 \\
\hline & & $\begin{array}{c}\text { Modelo estrutural - } \\
\text { executivo }\end{array}$ & 1 & & Não se aplica & 0 & 0 \\
\hline & & Modelo Civil -executivo & 1 & & Não se aplica & 0 & 0 \\
\hline & $\begin{array}{c}\text { Executar estimativa de } \\
\text { custos }\end{array}$ & $\begin{array}{c}\text { Estimativa de custos - } \\
\text { executivo }\end{array}$ & 1 & $\begin{array}{l}\text { Atividade não } \\
\text { desenvolvida }\end{array}$ & Não é desenvolvido & 0 & 1 \\
\hline & Executar coordenação 3D & $\begin{array}{c}\text { Modelo de coordenacao } 3 D \\
\text {-executivo }\end{array}$ & 1 & $\begin{array}{c}\text { Atividade não se aplica } \\
\text { a este processo }\end{array}$ & Não se aplica & 0 & 0 \\
\hline & $\begin{array}{l}\text { Desenvolver protótipo } \\
\text { virtual }\end{array}$ & Protótipo virtual -executivo & 1 & $\begin{array}{l}\text { Desenvolvimento do } \\
\text { protótipo }\end{array}$ & Modelo em cad 2D & 1 & 1 \\
\hline & Criar modelo 4D & Modelo 4D -executivo & 1 & $\begin{array}{l}\text { Atividade não } \\
\text { desenvolvida }\end{array}$ & Não é desenvolvido & 0 & 1 \\
\hline & $\begin{array}{c}\text { Executar análises de } \\
\text { engenharia }\end{array}$ & $\begin{array}{l}\text { Modelo de análises de } \\
\text { engenharia -executivo }\end{array}$ & 1 & $\begin{array}{l}\text { Atividade não } \\
\text { desenvolvida }\end{array}$ & Código CNC & 1 & 1 \\
\hline \multirow{4}{*}{ 贷 } & Produzir componentes & & & Produzir componentes & & & \\
\hline & Montar módulos & & & Montar módulos & & & \\
\hline & Instalar módulos & & & Instalar módulos & & & \\
\hline & Compilar "as built" & Modelo "as built" & 1 & Compilar "as built" & Modelo "as built" & 1 & 1 \\
\hline \multicolumn{3}{|c|}{ TOTAL - Usos potenciais } & 29 & \multicolumn{2}{|c|}{ Total - processos atuais e a implantar } & 10 & 19 \\
\hline & & $\%$ & 100 & & $\%$ & 34 & 66 \\
\hline
\end{tabular}

Fonte: os autores

Sendo a fabricação de cozinhas um sub-processo industrial dentro do processo completo de projeto e construção de que trata o guia, não é possível um enquadramento de $100 \%$ dos ítens. O potencial máximo que pode ser incorporado é cerca de $66 \%$ dos processos sugeridos 
pelo guia. Este percentual é obtido pela razão entre totais da coluna (8) e da coluna (4). Observa-se ainda, pela razão entre os totais da coluna (7) e da coluna (4) que atualmente a empresa se enquadra em cerca de $34 \%$ dos processos sugeridos pelo guia. Destaca-se ainda na Tabela 3, através das cores azul, laranja e cinza, respectivamente, os processos propostos pelo guia já incorporados na empresa em estudo, os processos que podem ser incorporados e os processos do guia BIM que não se aplicam ao sub-processo de fabricação digital de cozinhas.

Um modelo BIM contendo os móveis planejados poderá ser agregado ao processo principal onde participará das atividades de compatibilização, planejamento 4D, orçamentação e controle (5D) ou até eventualmente da operação e manutenção (6D). Esta visão da integração da Fabricação Digital no contexto proposto pelo guia CIC (2011) poderá ser aplicada em outros sub-sistemas pré-fabricados do edifício.

Em relação à atividade de estimativa de custo na fase do anteprojeto, mostrada na Tabela 3, a grande diferença entre o processo atual e o processo incorporando BIM são as ferramentas utilizadas. No processo atual são utilizadas planilhas desenvolvidas no software MS Excel nas quais se inserem dados extraídos dos desenhos 2D esquemáticos. No sistema BIM serão extraídos quantitativos a partir do modelo 3D anteprojeto. As atividades de executar estimativa de custo na fase de projeto básico e executar estimativa de custo na fase de projeto executivo serão elaboradas a partir dos quantitativos extraídos do modelo básico e do modelo executivo respectivamente, e não possuem correspondentes no sistema atual adotado pela empresa.

A partir da comparação dos mapas e tabelas apresentados anteriormente pode-se identificar diferenças entre escopo de atividades ${ }^{2}$, ferramentas ${ }^{3}$ utilizadas, os produtos ${ }^{4}$ e os agentes ${ }^{5}$. Tanto o mapa de processos atualmente adotados pela empresa (Figura 4), quanto o mapa de processo de execução BIM (Figura 5), se iniciam com a atividade de validação do programa que é detalhada na Figura 7. Nesta atividade não se observa diferenças significativas entre o sistema adotado pela empresa e o sistema proposto pelo Guia BIM. No processo de validação do programa, o cliente fornece ao arquiteto o layout dos ambientes, as dimensões e especificações técnicas relativas a instalação dos eletrodomésticos, os acessórios a serem incorporados nos módulos e a definição de materiais e tipos de acabamentos adotados. Estas informações são compiladas e discutidas com o departamento de engenharia e então apresentadas ao cliente para validação.

A Criação do Anteprojeto, Projeto Básico e Projeto Executivo apresentam diferenças significativas em termos de ferramentas e produtos. No sistema adotado, a ferramenta utilizada é o autoCAD e os produtos são desenhos 2D. No sistema BIM a ferramenta será um software 3D parametrizado e os produtos são modelos 3D parametrizados. O processo de criação de um modelo BIM é descrito na Figura 8. A leitura deste mapa mostra que a criação do modelo BIM requer a prévia verificação de que os elementos necessários fazem parte da biblioteca de objetos da ferramenta utilizada. Conforme mostra a Figura 8, o primeiro passo para a criação de um modelo BIM, é a identificação dos elementos requeridos para a criação do modelo. Estas informações permitem verificar se a biblioteca possui todos os elementos necessários. Esta função deverá ser desenvolvida por um profissional que possua conhecimentos avançados na ferramenta BIM utilizada. Após este processo o modelo é criado e verificado quanto ao atendimento das requisições iniciais.

\footnotetext{
2 Termo genérico para designar um trabalho ou ação que a empresa realiza. Uma atividade pode ser ainda uma composição de sub-atividades.

${ }^{3}$ Software ou tecnologia utilizados para a realização de uma atividade.

${ }_{4}^{4}$ Pode ser um artefato, um relatório ou uma informação que é um resultado de uma atividade ou um dado de entrada ou referência para a execução de uma atividade.

${ }^{5}$ Entidade, departamento ou indivíduo participante em um processo como sujeito de uma atividade.
} 
Figura 7 - Processo de execução BIM - Validação do Programa - Nível 2

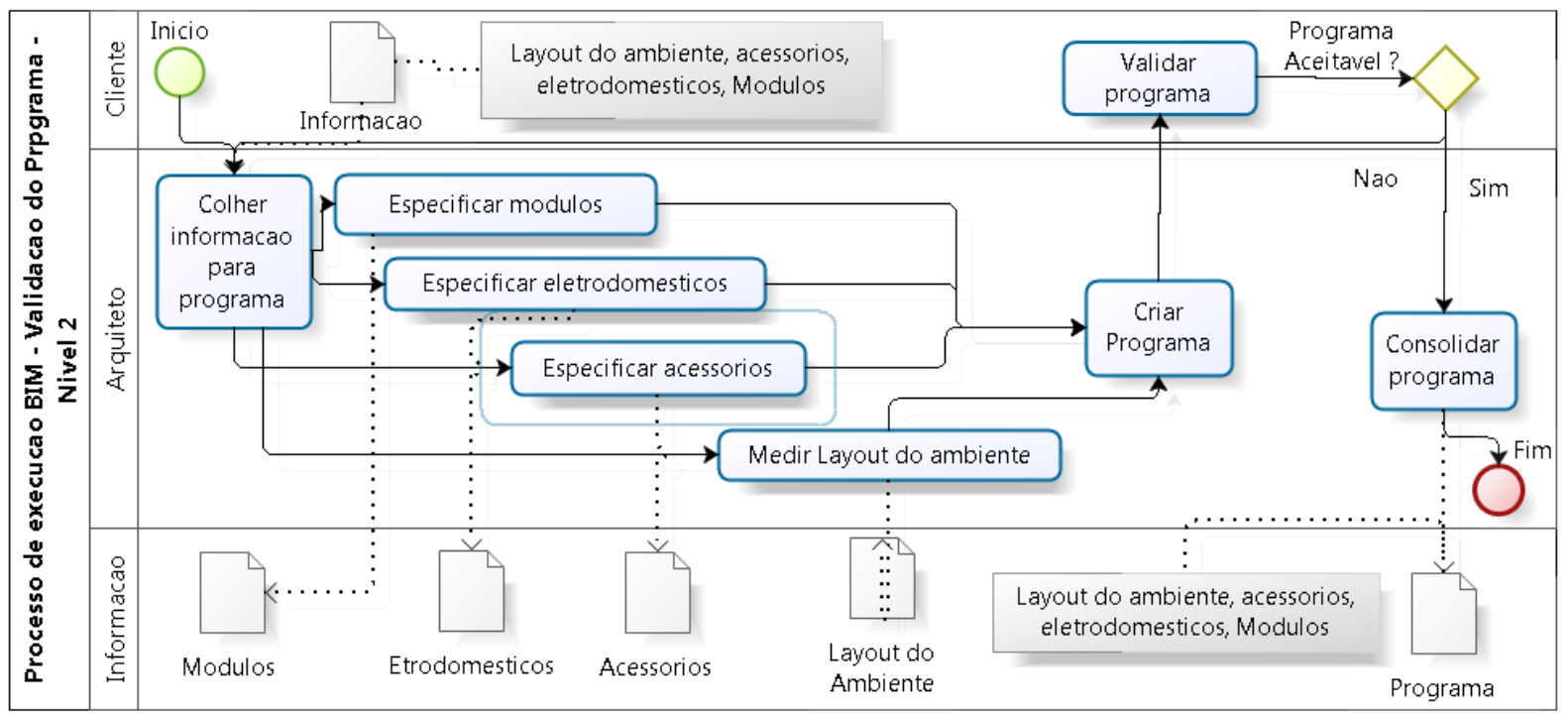

Fonte: os autores

Figura 8 - Processo de execução BIM - Criação dos modelos - Nível 2

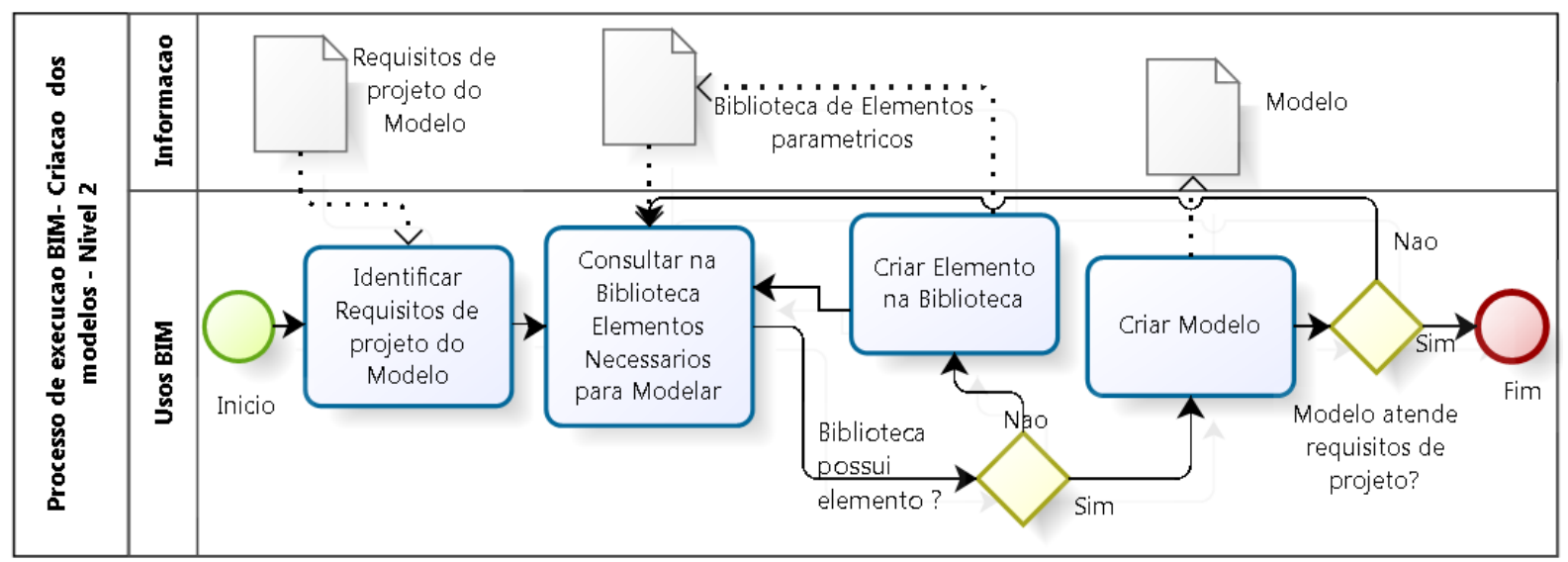

Fonte: adaptado de CIC (2011, p.96)

O processo de fabricação digital adotado pela empresa, tem como base os desenhos CAD 2D do projeto de produção e planilhas geradas a partir de uma biblioteca desenvolvida com o software MS Excel e programada com Visual Basic Application - VBA. A partir da consolidação destes documentos realizada visualmente pelo engenheiro, são geradas as listas de materiais e os códigos CNC de corte 2D e corte 3D. Os códigos para as máquinas 2D (serra de mesa) são gerados automaticamente com o auxílio do software ARDIS, especialista em otimização de cortes retangulares das chapas de madeira. O software ARDIS importa a lista de cortes retangulares a partir das planilhas Excel. Os códigos para as máquinas 3D (fresadora de 3 eixos) são gerados por um engenheiro especialista em programação CNC, que dedica tempo integral a esta atividade. Estes códigos são transferidos para a fábrica onde os operadores tem a única função de manter as máquinas em funcionamento, pois toda a programação é feita nos escritórios de projeto.

A grande diferença entre a fabricação digital praticada atualmente na empresa e a fabricação digital no processo BIM é que as informações de fabricação deixam de ser colhidas dos 
desenhos de projeto executivo para serem extraídas do Modelo 3D parametrizado. $\mathrm{Na}$ implantação BIM mudar-se-á a composição da equipe de engenharia adotada ,que é a de um engenheiro dedicado à geração de desenhos CAD 2D e planilhas Excel, e outro engenheiro dedicado à geração de códigos CNC. Passa-se a ter uma equipe em que ambos os engenheiros criam os modelos 3D e geram os códigos CNC. Para que este objetivo seja alcançado, um dos fatores cruciais na escolha do software de modelamento a ser adotado deverá ser a sua interoperabilidade com as máquinas $\mathrm{CNC}$ com as quais a empresa trabalha.

No processo de estimativa de custos adaptado do Guia BIM em CIC (2011), destaca-se a necessidade da criação de um banco de dados de custos, no qual será associada a lista de quantitativos extraída do modelo BIM. Dentro deste processo a atividade de Incorporação de Imprevistos e de Custos Indiretos, mostra a importância da conformidade dos resultados com os alvos de custos estabelecidos no início do processo de estimativas.

O critério de classificação das diferenças quanto ao impacto resultante da implantação do processo adaptado do Guia BIM $(\mathrm{CIC}, 2011)$ na empresa estudada, é apresentado na Tabela 1. (i) Uma atividade é de baixo impacto quando permanece inalterada após a implantação BIM; médio impacto é quando sofre pequenas alterações, e alto impacto quando é completamente alterada ou se trata de atividade inexistente antes da implantação BIM. (ii) Uma ferramenta recebe a classificação de baixo impacto se for um dispositivo físico ou mental que continua sendo usado da mesma maneira após a implantação BIM, uma ferramenta CAD/CAM recebe classificação de impacto médio, e uma nova ferramenta BIM recebe classificação de alto impacto. (iii) Um artefato físico ou intelectual que continua inalterado é um produto de baixo impacto; um desenho 2D ou código CAM que permanecem inalterados ou parcialmente alterados, constituem um produto de impacto médio; um produto novo gerado por uma ferramenta BIM tem alto impacto. (iv) Finalmente, quando a implantação BIM não requer o treinamento do agente que executa certa atividade, trata-se de um agente de baixo impacto; se for requerido um treinamento básico de operação de algum software por exemplo, este agente tem um impacto médio, mas se for requerido um treinamento exaustivo do agente para que ele se habilite a executar a atividade, este agente recebe uma classificação de alto impacto.

Cada categoria de diferença de impacto (escopo da atividade, ferramenta, produto e agente) recebe uma pontuação conforme o impacto. Categoria que sofre baixo impacto recebe 1 ponto; categoria que sofre médio impacto recebe 2 pontos e categoria que sofre alto impacto recebe 3 pontos. Os processos são listados em uma sequencia que começa com as etapas iniciais de concepção do empreendimento, indo além do seu término. Os relacionamentos entre os processos podem ser visualizados nos mapas apresentados anteriormente.

Cada processo, agrupado conforme a fase no ciclo de vida do empreendimento, é codificado conforme categoria de diferença de impacto. A codificação dos impactos é mostrada na Tabela 4 onde nota-se que a categoria ferramentas sofre o maior impacto. Observa-se ainda que os processos que recebem a maior pontuação possível de impacto são aqueles inexistentes antes da implantação BIM. As atividades relativas à fase de fabricação são as que tem menor impacto na implantação de BIM.

\section{CONCLUSÃO}

Na formulação do problema deste estudo foi feita a seguinte pergunta: De que forma BIM impacta o processo de fabricação digital? Observou-se que o impacto da implantação BIM na fabricação digital de móveis modulados é considerável, de médio para alto, sendo médio nas categorias Escopo da atividade e Produtos e alto nas categorias Ferramentas e Agentes.

As prioridades da implantação de cada uso BIM apresentadas na quarta coluna da Tabela 2 (alta, média, baixa), que foram definidas conforme o interesse imediato da empresa, que é a 
integração dos processos de projeto ao sistema de Fabricação Digital, apresentam o caminho de transição incremental para se adotar os potencias usos BIM identificados na oitava coluna da Tabela 3.

Tabela 4 - Codificação de impactos de cada uso BIM

\begin{tabular}{|c|c|c|c|c|c|c|}
\hline \multirow{2}{*}{ Ð } & \multirow{2}{*}{ Potencial uso BIM } & \multicolumn{5}{|c|}{ Impacto } \\
\hline & & $\begin{array}{l}\text { Escopo da } \\
\text { atividade }\end{array}$ & Ferramenta & Produto & Agente & $\begin{array}{l}\text { Total por } \\
\text { processo }\end{array}$ \\
\hline \multirow{6}{*}{$\begin{array}{l}\frac{0}{0} \\
\frac{0}{0} \\
\frac{0}{0} \\
\stackrel{0}{0} \\
\frac{1}{c}\end{array}$} & Validação do programa & 1 & 1 & 1 & 1 & 1 \\
\hline & Produzir Anteprojeto & 1 & 3 & 3 & 2 & 2,3 \\
\hline & Executar estimativa de custos & 1 & 3 & 1 & 2 & 1,8 \\
\hline & Desenvolver protótipo virtual & 3 & 3 & 3 & 3 & 3 \\
\hline & Criar modelo 4D & 3 & 3 & 3 & 3 & 3 \\
\hline & $\begin{array}{l}\text { Desenvolver simulação de } \\
\text { iluminação }\end{array}$ & 1 & 3 & 1 & 3 & 2 \\
\hline \multirow{5}{*}{ 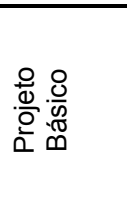 } & Produzir Projeto Básico & 2 & 3 & 3 & 3 & 2,8 \\
\hline & Desenvolver orçamento básico & 3 & 3 & 2 & 2 & 2,3 \\
\hline & Desenvolver protótipo virtual & 3 & 3 & 3 & 3 & 3 \\
\hline & Criar modelo 4D & 2 & 3 & 3 & 3 & 3 \\
\hline & $\begin{array}{l}\text { Desenvolver simulação de } \\
\text { iluminação }\end{array}$ & 3 & 3 & 3 & 3 & 3 \\
\hline \multirow{4}{*}{ 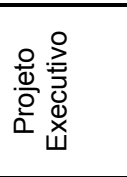 } & Produzir Projeto Executivo & 3 & 3 & 3 & 3 & 3 \\
\hline & $\begin{array}{l}\text { Desenvolver orçamento } \\
\text { detalhado }\end{array}$ & 2 & 3 & 2 & 2 & 2,3 \\
\hline & Desenvolver protótipo virtual & 3 & 3 & 3 & 3 & 3 \\
\hline & Criar modelo 4D & 1 & 3 & 1 & 2 & 1,8 \\
\hline \multirow[t]{2}{*}{ Fabricação } & Compilar modelo "as built" & 1 & 2 & 2 & 2 & 1,8 \\
\hline & Impacto por categoria & 2,1 & 2,8 & 2,3 & 2,5 & \\
\hline
\end{tabular}

Fonte: os autores

Sendo a fabricação de cozinhas um sub-processo dentro do processo completo de projeto e construção de que trata o guia, não é possível um enquadramento de $100 \%$ dos ítens. Observou-se que o potencial máximo que pode ser incorporado é cerca de $66 \%$ dos processos sugeridos pelo guia. Verificou-se também que atualmente a empresa se enquadra em cerca de $34 \%$ dos processos sugeridos pelo guia. Apontous-e dentre os processos propostos pelo guia os já incorporados na empresa em estudo, os processos que podem ser incorporados e os processos do guia BIM que não se aplicam ao sub-processo de fabricação digital de cozinhas.

Um modelo BIM contendo os móveis planejados poderá ser agregado ao processo principal onde participará das atividades de compatibilização (identificação de interferências), planejamento 4D, orçamentação e controle (5D) ou até eventualmente da operação e manutenção (6D). Esta visão da integração da Fabricação Digital no contexto proposto pelo guia CIC (2011) poderá ser aplicada em outros sub-sistemas pré-fabricados do edifício.

Além deste diagnóstico, para o caso estudado, destaca-se como contribuições deste estudo a geração de tabelas de impactos na implantação de BIM, a pontuação destes impactos e a criação de cenários de impactos.

\section{REFERÊNCIAS}

CIC - COMPUTER INTEGRATED CONSTRUCTION Research Program. BIM Project Execution Planning Guide. Version 2.0. The Pennsylvania State University, University Park, PA, USA, May 2011. Disponível em <http://bim.psu.edu/default.aspx>. Acesso em: 21 jul.2014. 
EASTMAN, C. et al. BIM handbook: a guide to Building Information Modeling for owners, managers, designers, engineers and contractors. New Jersey, USA. Ed. John Wiley \& Sons, Inc. (2008) ISBN: 978-0-470-18528-5 (cloth)

GERSHENFELD, N. How to Make Almost Anything: The Digital Fabrication Revolution, in: Foreign Affairs,New York,Nov. 2012, Vol 91, No.6, pp.43-57 Disponível em < http://search.proquest.com/docview/1223498609/fulltext/8183E9EEDE2147A1PQ/1? accountid=53268 \#> Acesso em: 23 Nov.2014

JIANG, X. Developments in Cost Estimating and Scheduling in BIM technology, Thesis-Master of Science in Civil \& Environmental Engineering, Northeastern University, Boston-MassachusettsUSA, 2011, Disponível em <www.proquest.com>, Acesso em: 25 Nov.2014

KOLAREVIC, B (Ed.). Architecture in the Digital Age - Design and Manufacturing, First Published, New York, Spon Press, 2003, ISBN 0.415.27820-1, Disponível em < http://gsappworkflow2010.files.wordpress.com/2010/09/kolarevic-architecture-in-the-digital-age1.pdf>, Acesso em: 25 Nov.2014

NAHMENS, I; BINDROO, V. Is customization fruitful in industrialized homebuilding industry? In: Journal of Construction Engineering and Management, American Society of Civil EngineersASCE, 2011, vol 137, issue 12, Disponível em <ascelibrary.org> Acesso em: 9 dez.2014

SUCCAR, B. Building information modelling framework: A research and delivery foundation for industry stakeholders. Automation in Construction, v.18,n.3, p.357-375, 2009. ISSN 0926-5805

WHITE S. A. Introduction to BPMN, IBM Corporation, May 2004. Disponível em < http://www.omg.org/bpmn/Documents/Introduction_to_BPMN.pdf >. Acesso em: 26 maio.2015 